\title{
SEPARATION OF LOCAL SIGNALS FROM THE REGIONAL PALEOMONSOON RECORD OF THE CHINESE LOESS PLATEAU: A ROCK-MAGNETIC APPROACH
}

\author{
Subir K. Banerjee and Christopher P. Hunt \\ Institute for Rock Magnetism and Department of Geology and Geophysics, University of Minnesota
}

Xiu-Ming Liu

Department of Geography, University of Liverpool

\begin{abstract}
We propose a method based on thermal unblocking of low-temperature saturation remanent magnetization for a quantitative estimation of the superparamagnetic [Cullity, 1972] fraction (size, $d<30 \mathrm{~nm}$ ) of magnetite produced by pedogenesis in the Chinese loess plateau [Liu, 1988]. We applied this method to the proxy climatic records of the last 130 ka from two sites $250 \mathrm{~km}$ apart, but separated by the mountain range Liupan-shan. Xifeng to the east $\left(35.7^{\circ} \mathrm{N}, 107.6^{\circ} \mathrm{E}\right)$ and Baicaoyuan to the west $\left(36.2^{\circ} \mathrm{N}, 105.0^{\circ} \mathrm{E}\right)$ currently have humid and arid microclimates, respectively. As expected, the superparamagnetic fraction increases during known warm temperature intervals at each site. Furthermore, the more humid site clearly has higher overall superparamagnetic fractions during most of the last $130 \mathrm{ka}$. However, during the period 5 to $10 \mathrm{ka}$ ago, the relative humidity at both sites was the same within experimental errors. Bulk grain size evidence confirms the magnetic data, and we suggest that the present easterly summer monsoon in China came from a more southerly direction during this time to flow parallel to Liupan-shan, resulting in very similar summer humidity at Xifeng and Baicaoyuan.
\end{abstract}

\section{Introduction}

The discovery of Milankovitch cycles [Wang et al., 1990] in the magnetic susceptibility $(\chi)$ record in the loess plateau of central China (Figure 1) and of a rough agreement [Heller and Liu, 1984] in number and age of the highs and lows between the magnetic susceptibility record and the warm and cold oxygen isotopic stages $\left(\delta^{18} \mathrm{O}\right)$ of the marine sediment record has raised our hopes of a precise correlation of the continental and oceanic paleoclimate change records for the Quaternary period [Hovan et al., 1991]. In addition, some [Heller et al., 1991] have drawn attention to the fluctuations in $\chi_{\mathrm{fd}}$ (relative percentage variation of $\chi$ when measured at 470 and $4700 \mathrm{~Hz}$ ) observed within a single high- $\chi$ layer, and have interpreted the $\chi_{\mathrm{fd}}$ peaks as representing finer-scale variations in temperature and humidity within a single interglacial or interstadial period.

The chief objections we have to using raw $\chi$ or $\chi_{\mathrm{fd}}$ fluctuations as linear measures of pedogenic intensity fluctuations are: (1) We currently have only a qualitative understanding of the origin of superparamagnetic magnetite through pedogenesis; (2) we do not have a comprehensive rock-magnetic model for predicting the magnitude of such variations; and (3) we do not have a magnetic method that provides a truly quantitative

Copyright 1993 by the American Geophysical Union.

Paper number 93GL00908

0094-8534/93/93GL-00908\$03.00 measure of the amount of all the superparamagnetic grains produced by pedogenesis [Heller et al., 1991; Maher and Taylor, 1988]. In this communication, we propose an alternative method based on thermal demagnetization of an isothermal remanent magnetization acquired at $15 \mathrm{~K}$, and a test of its validity when applied to a pair of sites where the past relative humidity variation could be predicted reasonably well.

Along with most authors of recent rock magnetic studies of Chinese loess and paleosol, we subscribe to the view that the observed $\chi$-fluctuations are not due to a mere concentration of a constant, uniformly-sized magnetite "rain" from the troposphere during warm interglacials and interstadials - periods that were characterized by reduced inputs of the less-magnetic wind-borne loess [Kukla et al., 1988]. Rather, we accept the overwhelming evidence [Hus and Han, 1992; Maher and Thompson, 1991; Maher and Thompson, 1992; Zhou et al., 1990] that during the interglacials and interstadials, higher temperature, and especially higher rainfall due to strengthened summer monsoons, are responsible for the alteration of nonmagnetic (paramagnetic) iron-bearing silicate minerals such as feldspars and clays to strongly magnetic (ferrimagnetic) ultrafine grains of magnetite $\left(\mathrm{Fe}_{3} \mathrm{O}_{4}\right)$ or slightly oxidized cation-

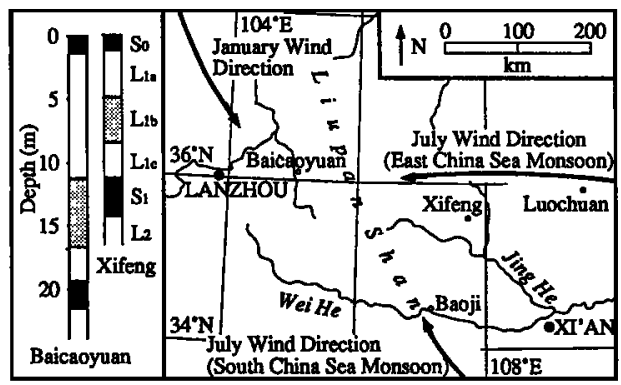

Fig. 1. The loess plateau in central China is more than $200 \mathrm{~m}$ thick at Xifeng and Baicaoyuan, and represents a continuous record of continental Quaternary climate for more than the last 2 Ma. Arrows show the average January wind direction which brings loess source material from the deserts to the northwest. The summer monsoon, which brings the humidity necessary for pedogenesis, can come from either the east or the south, depending on the relative positions of the Jet Stream and offshore high pressure systems [An et al., 1993]. The Liupan-shan range blocks the summer monsoon from the east, but not from the south. The loess and paleosol layers have been dated by a variety of methods including ${ }^{14} \mathrm{C}$, correlation with oceanic $\delta^{18} \mathrm{O}$ records, and magnetostratigraphy [Hovan et al., 1991; Liu, 1988], yielding basal ages of approximately 11 $k a$ for $S_{0}, 29$ ka for $L_{1 a}, 64$ ka for $L_{1 b}$ (a poorly developed paleosol within $\left.L_{1}\right), 75 \mathrm{ka}$ for $L_{1}$, and $128 \mathrm{ka}$ for $S_{1}$. 
deficient magnetite, compositionally intermediate between magnetite and maghemite $\left(\gamma-\mathrm{Fe}_{2} \mathrm{O}_{3}\right)$ [Singer and Fine, 1989]. For the purpose of this discussion, however, the exact composition of the magnetic products of pedogenesis does not matter. Prior work [Maher and Taylor, 1988] suggests that such pedogenic magnetite can range in size from a few hundred nm down to a few $\mathrm{nm}$, and that, depending on their exact shape and size, grains smaller than about $30 \mathrm{~nm}$ will be superparamagnetic-capable of producing high susceptibility and high induced magnetization, but not of retaining remanent magnetization. Grains larger than $30 \mathrm{~nm}$ but smaller than the pedogenic upper limit of nearly $100 \mathrm{~nm}$ will be either singledomain (carrying a uniform magnetic remanence) or pseudosingle-domain (consisting of only a few magnetic domains). In either case, the susceptibility will be lower (by a factor of 2-3) and the remanent magnetization higher (by a factor of 210) [King et al., 1982; Maher, 1988] than for superparamagnetic grains. With a few exceptions [Hus and Han, 1992], most authors until now have emphasized the use of high $\chi$ and $\chi_{\mathrm{fd}}$ values as indicators of pedogenesis. In a future communication, we propose to address the role of the larger pedogenic grains that can carry stable remanence.

\section{Susceptibility and its Frequency Dependence}

We chose Baicaoyuan (arid-350 mm/yr rainfall) and Xifeng (humid— $550 \mathrm{~mm} / \mathrm{yr}$ rainfall) [Liu et al., 1991] where prior stratigraphy and soil studies have resulted in the recognition of the coeval paleosol (S) and loess (L) horizons [Liu et al., 1992]. The intervening mountain, Liupan-shan (Figure 1) causes a rain-shadow at Baicaoyuan by obstructing the wet summer monsoon from the east [An et al., 1991]. Because of this, the paleomonsoon intensities and their pedogenic expressions ought to show a higher local signal at Xifeng. Figure 2 shows the variation of $\chi$ and $\chi_{\mathrm{fd}}$ with depth measured for single samples from each paleosol and loess horizon from the two sites. It is recognized that a single sample cannot display the natural variability inherent in a given layer, but each sample is nevertheless representative of each layer, as determined by previous more detailed work [Liu et al., 1991]. In contrast to conventional plots, $\chi$ is normalized by the saturation magnetization $\left(J_{\mathrm{s}}\right)$ so that the peaks in $\chi / J_{\mathrm{s}}$ represent true superparamagnetic contributions, not merely variations in the number of moderate-susceptibility multidomain grains $(>10 \mu \mathrm{m})$. The

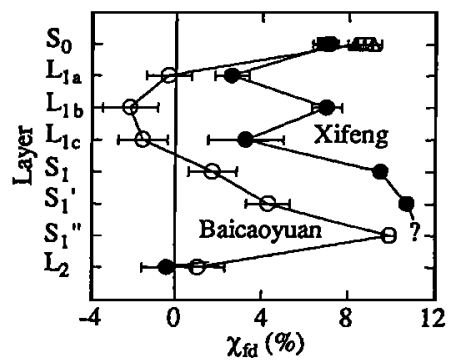

$\chi_{\mathrm{fd}}$ plot shows the reproducibility of each data point from an average of five repeat measurements on the same sample. Strictly speaking, $\chi_{\mathrm{fd}}$, as measured conventionally (and by us here) using just two frequencies, is only sensitive to the presence of magnetite grains between 18 and $20 \mathrm{~nm}$ [Néel, 1955], not to all superparamagnetic grains ( $30 \mathrm{~nm}$ to zero). In general, warm and humid intervals produce higher values of both $\chi / J_{\mathrm{s}}$ and $\chi_{\mathrm{fd}}$ at each site than cold and arid intervals, but the data also make clear that the humid site consistently yields higher values than the arid site. The important conclusion is that the magnetic proxy record anywhere in the Chinese loess plateau has a measurable, locally-controlled signal imposed on a regional signal controlled by the east Asian monsoon. Second, the disagreement in the amount of local signal measured by $\chi / J_{\mathrm{s}}$ and by $\chi_{\mathrm{fd}}$ cannot be resolved without a new method because neither of the parameters measures all pedogenic grains (both superparamagnetic below $30 \mathrm{~nm}$, and remanence-carrying between $30 \mathrm{~nm}$ and $100 \mathrm{~nm}$ ).

\section{Low-Temperature Remanence}

We therefore have addressed, as a first step, the problem of quantifying all of the superparamagnetic fraction by a lowtemperature technique. By definition, a ferrimagnetic mineral grain is superparamagnetic if its volume is smaller than the critical value $25 k T / K$ (where $k=$ Boltzmann's constant, $T=$ $300 \mathrm{~K}$ in this experiment, and $K=$ the magnetic anisotropy constant per unit volume), so that its net remanence over 100 sec is zero [Cullity, 1972]. However, as $T$ is decreased to 0 $\mathrm{K}$, the thermal energy $k T$ decreases and $K$ increases (both serving to aid magnetic stability), so that all grains which were superparamagnetic at $300 \mathrm{~K}$ will be able to retain thermallystable remanent magnetization near $0 \mathrm{~K}$. Two samples from Baicaoyuan —one a loess $\left(\mathrm{L}_{1 \mathrm{a}}\right)$ laid down during a cold epoch, and the other an overlying paleosol $\left(S_{0}\right)$ from the current warm epoch-were given a 2.5-T saturation remanent magnetization $J_{\mathrm{rs}}$ at $15 \mathrm{~K}$. Their relative loss of remanence on heating $\left(J / J_{\mathrm{rs}(15 \mathrm{~K})}\right)$ is shown in Figure 3. For comparison, a synthetic 50-50 mixture of 10-nm superparamagnetic magnetite and 1$\mu \mathrm{m}$ multidomain magnetite was subjected to the same treatment. Both the loess sample and the synthetic mixture contain coarser-grained magnetite as displayed by the sharp Verwey transition in the sign of $K$ at about $120 \mathrm{~K}$ [Cullity, 1972]. But, the superparamagnetic fractions in all three samples show

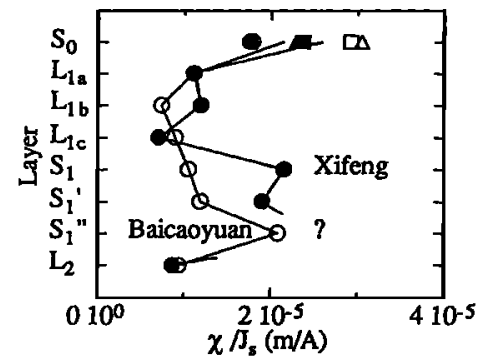

Fig. 2. Normalized magnetic susceptibility $\left(\chi / J_{\mathrm{s}}\right)$ and frequency dependence of magnetic susceptibility $\left(\chi_{\mathrm{fd}}=\left(\chi_{470 \mathrm{~Hz}}-\chi_{4700 \mathrm{~Hz}}\right)\right.$ $\times 100 \% / \chi_{470 \mathrm{~Hz}}$ ) as a function of depth. Squares and triangles in the $S_{0}$ layer represent duplicate samples. $S_{1}, S_{1}{ }^{1}$, and $S_{1}{ }^{\prime \prime}$ represent subhorizons in the $S_{1}$ layer, corresponding to marine isotope stages $5 \mathrm{a}, 5 \mathrm{c}$, and $5 \mathrm{e}$, respectively. The data from both sites show that more finer ferrimagnetic material is present in the paleosol layers than the loess layers, consistent with an increase in pedogenesis during warming and wetter times. Furthermore, evidence of pedogenesis is more abundant at the currently more humid site, Xifeng, except in $S_{0}$ time (5-10 ka). Both parameters give qualitative estimates of the presence of fine grains, but neither parameter provides a quantitative measure of the fine-grain fraction. 


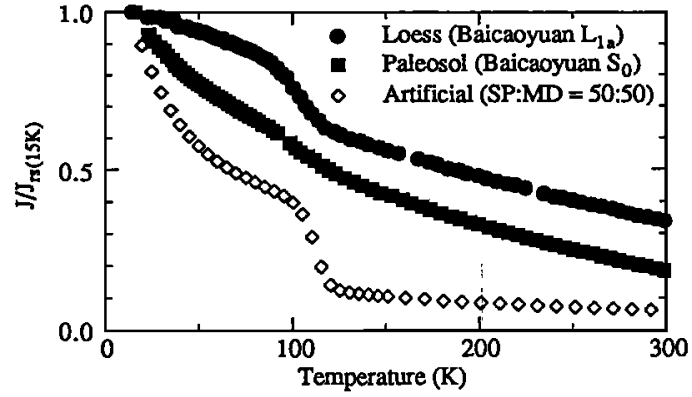

Fig. 3. In the low-temperature magnetic technique, a saturation remanence $\left(J_{\mathrm{rs}}\right)$ is applied at $15 \mathrm{~K}$ with a magnetic field of $2.5 \mathrm{~T}$. The sample is then warmed in a zero field to $300 \mathrm{~K}$. The Verwey transition near $120 \mathrm{~K}$ causes a dramatic loss of remanence in multidomain and certain single-domain grains ( $\geq 30 \mathrm{~nm}$ ), the magnitude of which depends partly on the grain size and the degree of grain oxidation. Smaller superparamagnetic grains lose their remanence with increasing temperature as they become thermally unstable and reach the blocking temperature appropriate to their size. The contribution to the remanence of superparamagnetic grains can be extracted by graphically subtracting both the value of the $300-\mathrm{K}$ remanence (from the whole curve) and the remanence lost during the Verwey transition (from the curve below about $100 \mathrm{~K}$ ). The loess sample and the paleosol sample both show the presence of large and small grains, but the paleosol displays the presence of relatively more superparamagnetic grains than the loess. An artificial mixture of 50\% (by weight) superparamagnetic (10-nm) magnetite ferrofluid and $50 \%$ coarse-grained (1- $\mu \mathrm{m})$ magnetite exhibits similar behavior.

a very rapid decay with increasing temperature, as expected from the thermal unblocking of $J_{\mathrm{rs}}$ carried by grains whose sizes are between 0 and $30 \mathrm{~nm}$. Thus, assuming the presence of only magnetite and maghemite with different grain sizes, we can calculate the relative $J_{\mathrm{rs}}$ contribution at $15 \mathrm{~K}$ due to all pedogenic superparamagnetic magnetite between 0 and $30 \mathrm{~nm}$ by either a graphical or a numerical method of separation of the coarser-grain contribution. Details of such methods can be found in Hunt and Banerjee [1992] and in Kletetschka et al. [1993].

\section{Discussion and Conclusions}

Figure 4 shows a comparison of the fraction of $0-\mathrm{K}$ remanence carried by superparamagnetic grains (SP/Total). As expected, SP/Total increases during warm, humid epochs compared with the cold, dry times at each site. The variation is more muted at Xifeng than at Baicaoyuan, probably because of the generally greater rainfall there. The situation can be clarified with a representative sample for $S_{1}$ " from Xifeng, now missing, and from multiple samples from each horizon. But the most interesting fact to emerge is the relative difference at almost all times between the two sites: Xifeng consistently shows a greater SP/Total value for all layers. The only exception is the $S_{0}$ layer, dated between 5 and $10 \mathrm{ka}$, where the two sites have the same value of SP/Total. Because this was surprising, replicate samples from additional horizons from the $\mathrm{S}_{0}$-layer were measured to confirm our earlier findings (triangles and squares in Figure 4). We find, therefore, that even though the current rainfall due to the east Asian monsoon is

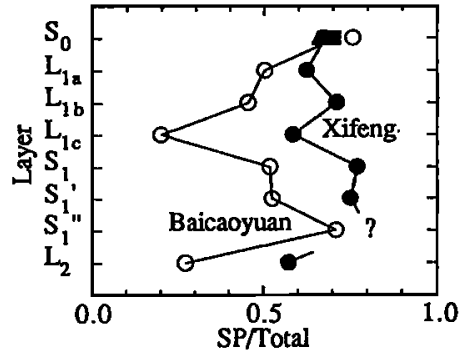

Fig. 4. Graphical analysis of the curves in Fig. 3 yields the proportion of the low-temperature remanence which is carried by grains with blocking temperatures between $0 \mathrm{~K}$ and 300 $\mathrm{K}$ - those grains which would be categorized as superparamagnetic at room temperature. Note the overall increase in the superparamagnetic fraction at Xifeng relative to Baicaoyuan, consistent with greater pedogenesis on the east side of the Liupan-shan. The exception again is $S_{0}$, suggesting that the relative amount of superparamagnetic-size magnetic material is the same at both sites between 5 and $10 \mathrm{ka}$.

different in the two sites, it would seem that the rainfall was the same between 5 and $10 \mathrm{ka}$ before present.

Confirmation of the results of our magnetic technique was found when, using a laser-light back-scattering technique [LAB-TEC ${ }^{\text {TM }}$, 1992], we measured the relative grain size distribution of the bulk sediments of the two sites from identical paleosol layers, $S_{0}$ and $S_{1}$ (Figure 5). When the magnetically derived pedogenic index, SP/Total, is the same (as in $S_{0}$ ), the
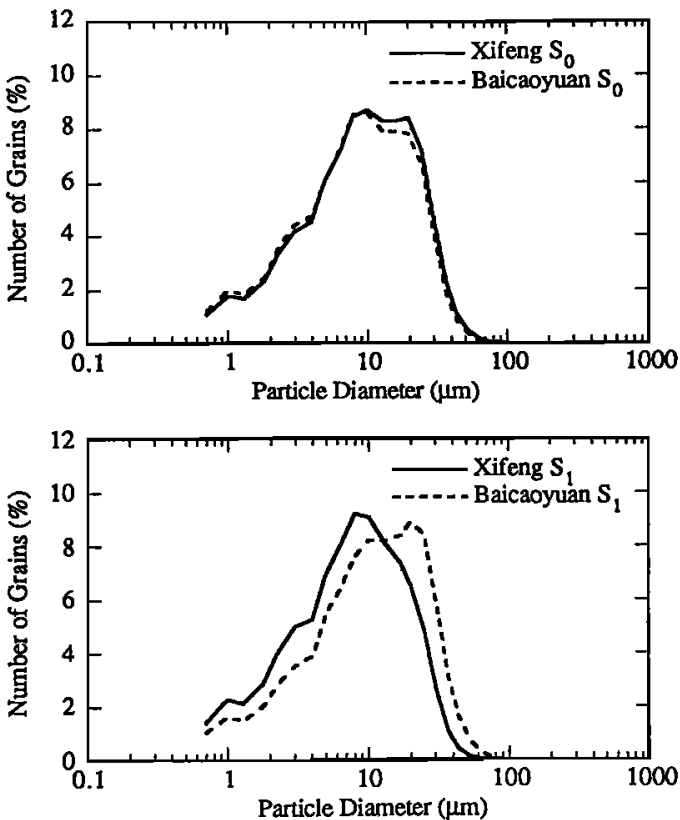

Fig. 5. The bulk grain-size distribution, measured non-magnetically using a laser light back-scattering technique [LABTEC $\left.^{\text {TM }}, 1992\right]$, is typical of loess in the central Chinese plateau. a, A comparison of the bulk grain-size distributions in the $S_{0}$ layers from Baicaoyuan and Xifeng reveals almost no difference-the soils are of equal maturity. b, A comparison of the $S_{1}$ layers reveals a marked contrast in soil development as revealed in the presence of more finer grains. These direct but destructive grain-size measurements confirm the results of the indirect but non-destructive magnetic technique. 
bulk grain-size distributions are also the same in the finest details. When the SP/Total fractions are different (as in $S_{1}, 30$ to $140 \mathrm{ka}$ ago), the bulk grain-size distributions are also different in the expected way - the more humid site has a greater proportion of finer grains.

We have shown that the low-temperature remanence method is sensitive enough to separate the local pedogenic signal from the regional east Asian monsoon intensity signals at two sites. Our study shows that the expected differences in past climate between the two sites is quantifiable, and should now be compared with sedimentological and chemical indices of soil maturation. Indeed, the technique used even detected unexpected results: between 5 and $10 \mathrm{ka}$ ago, comparable pedogenesis took place at sites that now have distinctly different microclimates. We therefore suggest that during the early Holocene, the current east Asian monsoon followed a more southerly track [An et al., 1993] parallel to the Liupan-shan, and produced identical pedogenesis at Baicaoyuan and Xifeng. Therefore, only after separating the local microclimate signal from the regional one can we use magnetic data for making conclusions about the intensity variations of the different interglacial climate regimes in the past. A comparative regional survey in the Chinese loess plateau, conducted along the lines of this study (now in progress), should yield both regional paleomonsoon signals and their local responses.

Acknowledgments. The authors would like to thank Bruce Moskowitz for many helpful discussions. This research was supported by a grant from the National Science Foundation and by the British SERC. This is publication number 9209 of the Institute for Rock Magnetism, which is funded by the W. M. Keck Foundation, The National Science Foundation, and the University of Minnesota.

\section{References}

An, Z.-S., G. J. Kukla, S. C. Porter and J. Xiao, Magnetic susceptibility evidence of monsoon variation on the loess plateau of central China during the last 130,000 years. $J$. Quat. Res., 36, 29-36, 1991.

An, Z.-S., S. C. Porter, W.-J. Zhou, Y.-C. Lu, D. J. Donahue, M. J. Head, X.-H. Wu, J.-Z. Ren and H.-B. Zheng, Episode of strengthened summer monsoon climate of Younger Dryas age on the loess plateau of central China. Quat. Res., 39, 45-54, 1993.

Cullity, B. D., Introduction to Magnetic Minerals. AddisonWesley, Reading, MA, 1972.

Heller, F. and T.-S. Liu, Magnetism of Chinese loess deposits. Geophys. J. R. Astr. Soc., 77, 125-141, 1984.

Heller, F., X.-M. Liu, T.-S. Liu and T.-C. Xu, Magnetic susceptibility of loess in China. Earth Planet. Sci. Lett., 103, 301-310, 1991.

Hovan, S. A., D. K. Rea and N. G. Pisias, Late Pleistocene continental climate and oceanic variability reconded in northwest Pacific sediments. Paleooceanogr., 6, 349-370, 1991.

Hunt, C. P., and S. K. Banerjee, Thermal demagnetization of low-temperature SIRM: a new method for magnetic granulometry (abstract), Eos Trans. Am. Geophys. Union, 73, no. 43 suppl., 138, 1992.
Hus, J. J. and J. Han, The contribution of loess magnetism in China to the retrieval of past global changes - some problems. Phys. Earth Planet. Inter., 70, 154-168, 1992.

King, J. W., S. K. Banerjee, J. A. Marvin and Ö. Özdemir, A comparison of different magnetic methods for determining the relative grain size of magnetite in natural materials: some results from lake sediments. Earth Planet. Sci. Lett., 59, 404-419, 1982.

Kletetschka, G., B. M. Moskowitz, C. P. Hunt and S. K. Banerjee, Fourier analyses of thermal demagnetization of low-temperature SIRM: Method for estimating the amount of ultrafine grained magnetite in soils (abstract). Eos Trans. Am. Geophys. Union, 74, no. 4? suppl., ???, 1993.

Kukla, G. J., F. Heller, X.-M. Liu, T.-C. Xu, T.-S. Liu and Z.-S. An, Pleistocene climates dated by magnetic susceptibility. Geology, 16, 811-814, 1988.

LAB-TEC ${ }^{\text {TM }} 1000$ User's Manual, Laser Sensor Technology, Inc., 85 pp., Redmond, WA, 1992.

Liu, T.-S., Loess in China. Springer-Verlag, Berlin and Heidelberg, 1988.

Liu, X.-M., T.-S. Liu, J. Shaw, F. Heller, T.-C. Xu and B. Yuan, Paleomagnetic and paleoclimatic studies of Chinese loess. In Loess, Environment, and Global Change, edited by T.-S. Liu, pp. 61-81, Science Press, Beijing, 1991.

Liu, X.-M., J. Shaw, T.-S. Liu, F. Heller and Y. Baoyin, Magnetic mineralogy of Chinese loess and its significance. Geophys. J. Int., 108, 301-308, 1992.

Maher, B. A., Magnetic properties of some synthetic submicron magnetites. Geophys. J., 94, 83-96, 1988.

Maher, B. A. and R. M. Taylor, Formation of ultrafinegrained magnetite in soils. Nature, 336, 368-371, 1988.

Maher, B. A. and R. Thompson, Mineral magnetic record of the Chinese loess and paleosols. Geology, 19, 3-6, 1991.

Maher, B. A. and R. Thompson, Paleoclimatic significance of the mineral magnetic record of the Chinese loess and paleosols. Quat. Res., 37, 155-170, 1992.

Nél, L., Some theoretical aspects of rock magnetism. $A d v$. Phys., 4, 191-243, 1955.

Singer, M. J. and P. Fine, Pedogenic factors affecting magnetic susceptibility of northern California soils. Soil Sci. Soc. Am. J., 53, 1119-1127, 1989.

Wang, Y., M. E. Evans, N. Rutter and Z. Ding, Magnetic susceptibility of Chinese loess and its bearing on paleoclimate. Geophys. Res. Lett., 17, 2449-2451, 1990.

Zhou, L.-P., F. Oldfield, A. G. Wintle, S. G. Robinson and J. T. Wang, Partly pedogenic origin of magnetic variations in Chinese loess. Nature, 346, 737-739, 1990.

S. K. Banerjee and C. P. Hunt, Institute for Rock

Magnetism and Department of Geology and Geophysics, University of Minnesota, Minneapolis, MN 55455, USA X.-M. Liu, Department of Geography, University of Liverpool, Liverpool L69 3BX, UK

(Received February 9, 1993; revised March 18, 1993; accepted March 18, 1993) 